\title{
Overview of Research on Dual-Channel Supply Chain Management
}

\author{
LI Ying-ying ${ }^{1, a}$ \\ ${ }^{1}$ Business School, Fuyang Normal University, Fuyang Anhui 236000, China \\ a546480288@qq.com
}

Key words: dual-channel; hannel conflict; pricing strategy; coordination mechanism

\begin{abstract}
On the basis of systematically reviewing related literatures at home and abroad, this paper summarizes the current research on the selection of dual-channel supply chain, channel conflict, pricing strategy and coordination mechanism, and discusses the future research direction and hopes to lay a foundation for the follow-up research and development basis.
\end{abstract}

\section{Introduction}

With the rapid development of e-commerce and information technology, many well-known manufacturers (such as HP IBM Nike and Lenovo TCL, etc.) have been involved in e-commerce. They all began to increase the network direct sales channel based on traditional physical retail channels. The development of online sales channels has brought many benefits. On the one hand, direct sales network not only increases manufacturers' sales channels, but also reduces costs and increases efficiency so that it can achieve higher profits. On the other hand, direct sales channels Provide consumers with more purchasing channels, saving time and increasing utility. However, the network direct marketing channel also brought some problems. The direct marketing channel exacerbated the market competition, resulting in the traditional retail channels to the network of direct sales channels to resist the phenomenon.

For the study of dual-channel supply chain management, foreign countries started from Balasubramanian[1] on the price competition of dual channels in 1998. Since then, the research on dual channels in foreign countries has been increasing. The domestic market started from 2006 on the dual-channel supply chain management Research in recent years, with the continuous development of network technology, the research of dual-channel supply chain management has become one of the focuses of our country's scholars. Domestic and foreign research on dual-channel supply chain is mainly reflected in the decision-making of dual-channel supply chain, channel conflict of dual-channel supply chain, pricing strategy of dual-channel supply chain and coordination mechanism of dual-channel supply chain.

\section{Dual-channel supply chain management research}

2.1 Dual-channel supply chain selection problem research. Manufacturers can better understand consumers' needs and preferences through network direct sales channels and make more accurate forecasts of market demand accordingly. This not only improves consumer satisfaction but also improves market profitability, Therefore, the implementation of dual-channel supply chain has become a manufacturer to participate in market competition, a favorable means. However, some entity retailers began boycotting manufacturers' online direct sales channels. They thought that direct online sales channels pose a threat to physical retail channels, making the contradiction between dual-channel supply chains more prominent. This not only made the effect of dual-channel 
supply chain management impossible, But also led to the failure of the operation of the dualchannel supply chain. For example, photosynthesis, the largest private chain bookstore in China, had to declare a bankruptcy after the closure of all physical stores. Therefore, dual-channel supply chain management does not always have the advantage that manufacturers should consider whether they are in their own interests, whether it is acceptable to physical retail stores, and the overall performance of supply chain channels. At present, the inquiry into the double-channel problem has drawn many scholars' deep research. Park and $\mathrm{Keh}^{[2]}$ believe that manufacturers choose online direct sales is conducive to their own improvement, the overall performance of dual-channel supply chain management will increase, but the profits of traditional retailers is reduced. Chiang et al ${ }^{[3]}$ found that manufacturers have opened direct online channels to not only increase their own needs and profits, but also reduce the prices of traditional retailers. Chen Jing et al ${ }^{[4]}$ think that the network direct sales channels not only help manufacturers to reduce costs, increase profits, but also to avoid physical retail store market control. Yan Ruiliang et al ${ }^{[5]}$ believe that the manufacturers to carry out the network of direct sales channels can effectively promote the physical retail stores to improve service levels, lower market wholesale prices, the ultimate realization of profit sharing. Van Ball et $\mathrm{al}^{[6]}$ found that more than $20 \%$ of consumers in the dual-channel supply chain consisting of traditional physical retail outlets and online direct sales channels take "free-riding" behavior and "free-riding" activities weaken the entity The enthusiasm of the store makes the contradiction between the two channels more prominent. Ferech et al ${ }^{[7]}$ studied the issue of dual-channel distribution from the perspective of consumer purchasing behavior using structural equation modeling and multiple regression analysis. The results show that electronic distribution channels can not completely replace traditional distribution channels, and consumers prefer dual-channel distribution models. Szmerekovsky et $\mathrm{al}^{[8]}$ studied the decision-making problems of both manufacturers and retailers in advertising. Luo Meiling et $\mathrm{a}^{[9]}$ analyzed the impact of bidirectional free riding on the pricing, service and profit of all parties in the dual-channel supply chain and studied the preconditions for manufacturers to launch the direct marketing network. Huang Song et $\mathrm{al}^{[10]}$ showed that consumer preferences and demand changes will affect the price strategy of physical retail channels and the manufacturer's production strategy. Liu et al ${ }^{[11]}$ pointed out that retailers will use price discrimination measures to boycott manufacturers to launch online direct sales channels, and this measure is extremely unfavorable to retailers. Chen Yuan et al ${ }^{[12]}$ argue that the service competition of dual-channel supply chains makes the dual-channel supply chain superior to the single-channel supply chain, and when the consumer preference for online direct sales channels is higher, the profit of the dual-channel supply chain is higher high.

Nowadays, with the rapid development of e-commerce, there is a consensus that the dualchannel supply chain benefits both at home and abroad. It is believed that dual-channel supply chain is beneficial to increase the profits of manufacturers, but there are also some problems. What are the factors that affect the two-channel supply chain, and how to carry out the management of the twochannel supply chain under the condition of win-win situation of both parties and so on have not been studied in depth. Therefore, the manufacturer of dual-channel supply chain needs further study.

2.2 Pairs of channels of supply chain channel conflict research. In the dual-channel supply chain, manufacturers aim to maximize their own interests, making the contradiction between the dual marginal effects of the supply chain more prominent. As manufacturers and retailers sell the same products and serve the same customers, dual-channel Leading to the loss of customers in the traditional physical retail stores, thereby affecting the effective operation of the dual-channel supply chain. Therefore, how to make manufacturers to improve their own interests while mitigating 
double-channel conflict is crucial. Webb and Kevin ${ }^{[13]}$ argue that online direct sales channels can reduce channel conflicts through sound pricing strategies and brand differentiation. Chiang et al ${ }^{[3]}$ believe that developing a network of direct sales channels can increase manufacturers' ability to control the prices of physical retail stores. Kumar et al ${ }^{[14]}$ argue that manufacturers and physical retailers can benefit from dual-channel supply chains at the same time only if certain conditions are met. Cattanik et al ${ }^{[15]}$ pointed out that manufacturers can make the best of manufacturers, retailers and consumers by setting the right price. Karray ${ }^{[16]}$ studied whether cooperative advertising could reduce the conflict between retailers selling both private-brand and manufacturer-supplied products. Cai Gangshu and Zhang ${ }^{[17]}$ argue that consistent pricing and price discounts can mitigate channel conflicts and improve the overall performance of the supply chain. Liang et al ${ }^{[18]}$ pointed out that when the manufacturer's network direct selling cost satisfies a certain value, launching the online direct sales channel can benefit manufacturers, retailers and consumers together. Huang Guanghui et $\mathrm{al}^{[19]}$ from the perspective of consumer choice behavior, study the conflict between manufacturers and retailers in the two-channel supply chain. Guo Yajun et $\mathrm{al}^{[20]}$ based on consumer utility theory to study the causes of double-channel conflict and coordination methods.

Channel conflict in dual-channel supply chains will lead to a loss of profit for manufacturers and retailers and a decrease in supply chain performance. The literature mainly analyzes how to reduce channel conflicts in terms of pricing, brand differentiation and channel costs. In fact, there are other factors influencing the two-channel supply chain, so in-depth study on reducing conflicts in the two-channel supply chain is needed.

2.3 Double-channel supply chain pricing strategy research. In the literature of dual-channel pricing strategy research, scholars generally first define the demand function. Demand in dualchannel mode is affected by many factors. There has not been a unified expression in the literature research all the time, because the different characteristics of the channels lead to the different definition and composition of the requirements. Dumrongsiri et al ${ }^{[21]}$ studied the quality of service, the conditions for manufacturers to join the sales channel, and the dual-channel pricing strategy. Huang and Swaminathan ${ }^{[22]}$ studied a single-layer, dual-channel pricing strategy. Weitz et al ${ }^{[23]}$ found that enterprises in the distribution through different channels to implement the same price strategy. Webb et al ${ }^{[24]}$ think that the price difference between channels can be controlled within the appropriate range through the price corridor way to realize the differential pricing of channels. Cattain et $\mathrm{a}^{[15]}$ concluded that in order to mitigate the channel conflict, the promised price of setting a direct sales channel matched the retail price of traditional channels. Kurata et al ${ }^{[25]}$ considered pricing decisions for products in an environment where both channel competition and brand competition coexist, pointing out that wholesale price subsidy contracts can coordinate the supply chain. Hua Guowei et al $^{[26]}$ think that the optimal time and price can be studied from two aspects: centralized and decentralized. Ding Zhengping et $\mathrm{al}^{[27]}$ analyzed the pricing equilibrium of decentralized decision making under different dual-channel structures, and found that the revenuesharing contract can fully coordinate the supply chain in decentralized decision making. In centralized decision-making, the supply chain can be realized through price difference Complete coordination. When adopting free riders, consumers propose the equilibrium price under the decentralized decision-making of the three supply chains and propose the pricing strategy to maximize the overall profit of the dual-channel supply chain. Fan Xiaojun et al ${ }^{[28]}$ studied the pricing and service competition strategies of dual-channel supply chain by analyzing consumer service preferences. Yan Nina et al ${ }^{[29]}$ studied the issue of price coordination in a dual-channel supply chain. Huang et al $^{[30]}$ studied the impact of cooperative advertising decisions on channel supply chain pricing decisions. Chen et al ${ }^{[31]}$ studied the pricing decisions of dual-channel retailers 
based on consumer utility theory and found that, compared with other retailers, Retailers will be priced high.

The existing literature has analyzed the influence and function of the double channel from different angles. By analyzing the channel pricing game and comparing the different advantages of the channel, the article provides the advice of the channel pricing decision. However, there are still many deficiencies in the existing research, such as neglecting or weakening the behavior of consumers during the purchase, and less consideration of the wholesale price.

2.4 Double Channel Supply Chain Coordination Mechanism. Although the dual-channel model of online direct selling and traditional distribution has become a major feature of marketing in today's manufacturing enterprises, the emergence of direct selling channels will inevitably compete with traditional distribution channels, triggering a key issue in dual-channel markets: channel conflict. Therefore, the issue of coordination of channel conflicts has become a hot issue in dual-channel research.

Chu and Desai ${ }^{[32]}$ studied a channel coordination mechanism based on customer satisfaction, believing that manufacturers can promote retailers to improve customer satisfaction and achieve Pareto improvement of both parties' returns according to retailer's effort cost and effort, and utilize two Pricing contracts study the coordination of the supply chain and find that the two pricing schemes can coordinate the supply chain. Raju and Zhang ${ }^{[33]}$ studied the quantity discount and two pricing contracts to coordinate the supply chain for the strong retailers in the supply chain. Kurata and $\mathrm{Yao}^{[34]}$ pointed out that under the channel price competition, the combined use of price discount and price premium compensation can coordinate the two-channel supply chain. Cho and Gerchak ${ }^{\text {[35] }}$ studied the retailer's cost-reduced innovation investment and studied the retailer's variable costs under the condition of linear and nonlinear function channel coordination. Tsay and Agrawal[36] think that the online direct sales channels and the traditional distribution channels are both extrinsic to sales promotion. However, the retail channel promotion has the cost advantage. The replenishment price plus the wholesale price contract can coordinate the supply chain. Qin Geng et $\mathrm{al}^{[37]}$ studied the equilibrium of price competition and supply chain coordination under random demand and retailer promotion. Yang et al ${ }^{[38]}$ analyzed the effect of fairness on cooperative advertising strategy and supply chain coordination in view of cooperative advertising in the case of retailers considering fairness. Yao et $\mathrm{al}^{[39]}$ used a repo strategy to analyze the supply chain and Seifert et $\mathrm{al}^{[40]}$ used a compensation strategy to coordinate the two-channel supply chain. Chen and $\mathrm{Xiao}^{[41]}$ studied the coordination mechanism of a dominant retailer in the supply chain when demand perturbed. Xiao and $\mathrm{Qi}^{\left[{ }^{[42]}\right.}$ proved that the use of discount discounts can coordinate the supply chain when costs and demand simultaneously perturb. Cao et al ${ }^{[43]}$ studied the coordination problem of VMI supply chain. The study found that using VMI alone could not effectively improve the efficiency of supply chain. Only with the revenue sharing contract can we coordinate the activities among supply chain members. Wang Hong et $\mathrm{al}^{[44]}$ discussed the conditions for establishing direct sales channels, pricing of channels and the coordination of wholesale price contracts in the supply chain based on the dual-channel supply chain in which suppliers are risk averse. Xiong Zhongkai et al ${ }^{[45]}$ studied supply chain coordination based on dynamic pricing in the network environment. The study found that revenue sharing can not achieve supply chain coordination, revenue sharing and rebate contracts can achieve supply chain coordination. Xie Qinghua and Huang Peiqing ${ }^{[46]}$ studied the issue of double-channel coordination based on quantity discount and found that there is an infinite number of contracts for the quantity discount of coordinated dual-channel supply chain. Liu et al ${ }^{[47]}$ studied dual-channel supply chain decisionmaking in the presence of service competition and service spillover effects, and used revenue- 
sharing contracts to coordinate the supply chain. However, Bin et al ${ }^{[48]}$ studied the compensation strategy for the coordination of the two-channel supply chain, and demonstrated that the compensation strategy can achieve the coordination of the two-channel supply chain and ensure a win-win situation for the members of the two-channel supply chain within a certain range.

In domestic and foreign literature, there are many coordination strategies on a single channel. However, in the dual-channel supply chain, the manufacturer is not only the retailer's supplier but also the retailer's competitor, resulting in the dual upstream and downstream in the dual-channel supply chain Marginalization problems exist at the same level of channel conflicts, so the general supply chain contract will not be able to coordinate dual-channel supply chain. Double-channel supply chain pricing decision-making and coordination of much academe attention, but also formed a number of research results. However, the research at this stage is mainly focused on the discussion under some specific assumptions, and the results are often difficult to apply to reality.

\section{The future research prospect of dual-channel supply chain management}

3.1 Consider increasing the diversity of objects. Most of the current research is a two-channel supply chain of a manufacturer and a retailer, less research for multiple manufacturers and retailers, and does not consider the problem of a manufacturer may have multiple traditional distribution channels for this In more complicated cases, the research of supply chain is also more complicated. For example, whether a manufacturer can coordinate with many retailers or retailers whether there are differences or differences will affect the manufacturer's decision-making, a large amount of literature has studied the consumption The preference of the channel, the difference of channel service, and the conclusion that putting these factors into the more complex supply chain can all be used as the research direction in the future.

3.2 Consider the diversity of influencing factors. Based on the previous literature review, it can be found that a large number of literature consider the factors are relatively single, consider a single product more, with fewer differences in the product, the majority of literature is more emphasis on consumer preferences to the channel, channel service differences These two factors to study the decision-making of dual-channel supply chain, did not consider more shadow. In the future, more influential factors will be included in the research so as to be more realistic.

3.3 Consider free ridership. The low price of network marketing channel leads to the emergence of free ride behavior. However, the research on dual channel supply chain nowadays does not pay much attention to the impact of free ride on dual channel supply chain, especially in domestic literature And this aspect. For future research, under the assumption of free ridership, it is possible to study how manufacturers and retailers cooperate to make the supply chain be coordinated, and free riders can occur either unidirectionally or bidirectionally. One-way free riders typically put retailers at risk, and there is a reasonable mechanism for making both parties profitable by minimizing such behavior. Free ride behavior in line with the actual situation, the study of this issue is also of great significance.

3.4 Consider the diversity of products. In the dual-channel supply chain system where the network channel and the traditional channel coexist, product differentiation leads to more competition in the supply chain system. However, the product differentiation has a different effect on the profit of different members. In a manufacturer-dominant supply chain system, manufacturers can influence consumers' value judgments on different products through marketing strategies such as advertisement diffusion and expand the influence of private brands in the network direct sales channels. Through the implementation of product differentiation strategy, Manufacturers can get higher profit levels. Retailers through the buy-out procurement and other means to achieve a 
monopoly sales of certain types of products, excluding channels of competition in other differentiated products, but also conducive to its high profits.

3.5 Consider the dual-channel cooperation model innovation. Compared with a single channel, dual channels can improve the profitability of manufacturers and the overall performance of the supply chain. Therefore, the coordination of supply chain is mostly the contractual mechanism that considers the profit distribution of supply chain members. There is almost no research on how to make a big cake in a double-channel setting. Although there are conflicts between the two channels, the dual channels have different advantages and disadvantages of different channels. For example, the virtual online channels can save space, display a large number of products, and the offline physical stores can provide intuitive feelings and services. The online channels You can shop anywhere, make full use of fragmentation time, offline store can quickly meet the customer's daily consumption and so on. Taking full account of the advantages and disadvantages of the dual channels and analyzing the new forms of cooperation under the dual channels, this is also an important direction that needs to be studied in the future.

\section{References}

[1] BALASUBURAMANIAN S. Mail versus mall: A strategy analysis of competition between direct marketers and conventional retailers [J]. Marketing Science ,1998, 17(3):181-195.

[2] PARK H T K,KEH H T. Modeling hybrid distribution channels a game-theoretic analysis [J]. Journal of Retailing and Consumer Services, 2003, 10(3):155-16.

[3] CHIANG W K.CHHAJED D ,HESS J D. Direct marketing indirect profits a strategy analysis of dual-channel supply chain design [J].Management Science 2003, 49(1):1-20.

[4] Chen Jing, Zhang Hui, Sun Ying. Implementing coordination contracts in a manufacturer stackelberg dual-channel supply chain [J].Omega,2012, 40(5):571-583.

[5] Yan Ruiliang, Pei Zhi . Retail services and firm profit in a dual-channel market[J]. Journal of Retailing and Consumer Services,2009,16(4): 306-314.

[6] VAN B S,DACH C. Free riding and customer retention across retailers' channels [J]. Journal of Interactive Marketing,2005,19(2):75-85.

[7] Fruchter G E, Tapiero C S. Dynamic Online and Offline Channel Pricing for Heterogeneous Customers in Virtual Acceptance[J].International Game Theory Review,2005,2(7):135-150.

[8] Szmerekovsky, J. G. , Zhang J. . Pricing and two-tier advertising with one manufacturer and one retailer [ J] .European Journal of Operational Research, 2009, 192:904- 917.

[9] LUO Meiling ,LI Gang. The bidirectional free-riding in a dual-channel supply chain[J].Journal of Systems Management,2014,23(3): 314-323,338.

[10] Huang Song, Yang Chao, Zhang Xi. Pricing and production decisions in dual-channel supply chains with demand disruptions [J].Computers and Industrial Engineering,2012,62(1):70-83.

[11] LIU Y,ZHANG Z J. Research note-the benefits of personalized pricing in a channel[J].Marketing Science,2006,25(1):97-105.

[12] CHEN Yuan-Gao, LIU Nan.Competitive Strategy of Dual-channel Supply Chain with Service Differences [J] .Computer Information Engineering, 2010,16(11):2484-2489.

[13] WEBB,KEVIN L. Managing channels of distribution in the age of electronic commence [J].Industrial Marketing Management,2002,31(3):95-102. 
[14] Kumar N, Ruan R R. On manufactures complementing the traditional retail channel with a direct online channel [J].Quantity Market Economics,2006(4): 289-323.

[15] CATTANI K,GILLAND W, HEESE $\mathrm{H}$, et al. Boiling frogs: pricing strategies for a manufactures adding a direct channel that competes with the traditional channel [J].Production and Operations Management,2006,15(1):40-56.

[16] Karray, S. , Zaccour , G. . Could co-op advertising be a manufacturer's counter strategy to store brands? [ J]Journal of Business Research, 2006, 59 ( 9) : 1008 -1015.

[17] Cai Gangshu, Zhang Z G, Zhang M. Game theoretical perspectives on dual-channel supply chain competition with price discount and pricing schemes [J].International Journal of Production Economics, 2009, 117(1): 80-96.

[18] LIANG Xi, HUANG Cheng-Feng, XIE Shui-Qing.Direct Channel Cost in Double-Channel Supply Chain and Its Impact on Sales Channel Decision [J]. Industrial Engineering, 2010-13 (4) : 32-36.

[19] Huang Guanghui, Wan Jianping, Cai Jianhu.Cooperation or Competition: Choice of Cost Decision Strategy - Design of Dual-Channel Logistics Supply Chain under Individual Selection of Consumers [J]. Journal of Management Engineers, 2006, 20(4) :139 - 141.

[20] Guo Y J, Zhao L Q. The Conflict and Coordination in Dual-Channel Based on e-market[J] . System Engineering -Theory \& Practice, 2008, 28( 9): 59- 66.

[21] Dumrongsiri A, Fan M, Jain A, et al. A supply chain model with direct and retail channels[J].European Journal of Operational Research,2008,187(3):691-718.

[22] Huang W, Swaminathan J M, Introduction of a second channel: Implications for pricing[J].European Journal of Operational Research,2009,194:258-279.

[23] WEITZ B A, JAP S D. Relationship Marketing and Distribution Channels [J] . Journal of the Academy of Marketing Science. 1995, 23 (4) : 305 - 320.

[24] WEBB K L, LAMBE C J. Internal multi - channel conflict: An exploratory investigation and conceptual framework [J]. Industrial Marketing Management. 2007, 36 ( 1) : 29 - 43.

[25] Kurata H, Yao D Q, Liu J J. Pricing Policies Under Direct vs. Indirect Channel Competition and National v s. Store B rand Competition [ J] . European Journal of Operational Research, 2007, 180( 1): 262- 281.

[26] HUA G, WANG S, CHENG T C E. Price and lead time decisions in dual - channel supply chains [J] . European Journal of Operational Research. 2010, 205 ( 1) : 113 -126.

[27] DING Zhengping, LIU Yezheng. Revenue sharing contract in dual-channel supply chain in case of free riding [J],Journal of Systems Engineering 2013,28(3):370-376.

[28] Fan Xiaojun, Liu Yan. Manufacturers Introduce Dual-channel Online Double-channel Price and Service Competition Strategy [J]. Chinese management science, 2016,24(7):143-148.

[29] Yan N N, Huang X Y, Liu B. Stackelberg game models of supply chain dual-channel coordination in e-markets [J],Chinese Journal of Management Science ,2007(3):98-102.

[30] Chen Y, Wang H C, Shen H Z. Study on the Pricing Strategy of Multi -channel Retailer in Internet Environment[ J] . Journal of Industrial Engineering Management, 2008, 22(1): 34- 39.

[31] Huang Song, Yang Chao, Zhang Xi. Pricing and Cooperative Advertising Decision Model in 
Dual-channel Supply Chain [J]. Computer Integrated Manufacturing System. 2011 ( 12) : 2683 -2692 .

[32] Chu W J. , Desai P S. Channel coordination mechanisms for customer satisfaction [J]. Marketing Science, 1995, 14 ( 4 ):343 - 359.

[33] Raju J. , Zhang Z J. Channel coordination in the presence of a dominant retailer [J]. Marketing Science, 2005, 24 ( 2 ): 254 -262.

[34] Kurata H. , Yao DQ. , Liu J J. Pricing policies under direct vs indirect channel competition and national vs store brand competition [J]. European Journal of Operational Research, 2007, 180 (1):262 -281.

[35] Cho K R, Gerchak Y. Supply chain coordination with downstream operating costs: Coordination and investment to improve downstream operating efficiency $[\mathrm{J}]$. European Journal of Operational Research, 2005, 162(3) :762 - 772.

[36] TSAY A A, AGRAWAL N. Channel Conflict and Coordination in the E -Commerce Age [J] . Production \& Operations Management. 2004, 13 ( 1): $93-110$.

[37] Qin Geng, Malik S. Inventory competition and allocation in a multi-channel distribution system [J]. European Journal of Operational Research, 2007, 182(2): 704-729.

[38] Yang J, Xie J, Deng X, et al. Cooperative advertising in a distribution channel with fairness concerns [J]. European Journal of Operational Research, 2013, 227(2): 401-407.

[39] Yao D Q, Yue X, Wang X Y, et al. The impact of information sharing on a returns policy with the add it ion of a direct channel $[\mathrm{J}]$. International Journal of Production Economics, 2005, 97( 2): 196 -209.

[40] Seifert R W, Thonemann U W, Sieke M A. Integrating direct and indirect sales channels under decentralized decision - making $[\mathrm{J}]$. International Journal of Production Economics, 2006, 103( 1) : 209-229.

[41] Chen K B, Xiao T J. Demand disruption and coordination of the supply chain with a dominant retailer [J] . European Journal of Operational Research, 2009, 197(1) : 225234.

[42] Xiao T J, Qi X T. Price competition, cost and demand disruptions and coordination of a supply chain with one manufacturer and two competing retailers $[\mathrm{J}]$. The International Journal of Management Science, 2008, 36( 5):741-753.

[43] CAO Wu-jun, LI Cheng-gang, WANG Xue-lin.Analysis of Revenue Sharing Contracts in VMI [J]. Journal of Management Engineering, 2007, 21(1):51 -55.

[44] W ang H, Zhou J. Coordination and Pricing Decision of Dual Channel [45]with Risk Averse Supplier [J] . Soft Science, 2008, 22( 11): 10- 12.

[45] Xiong Zhongkai, Li Gendao, Tang Yanchang, Li Wei.Study on Channel Coordination Considering Dynamic Pricing in Network Environment [J]. Chinese Journal of Management Engineering, 2007, 21(3):49 -55.

[46] Xie Qinghua, Huang Peiqing.Quality Discount Model for Channel Coordination in Hybrid Market under Internet Environment [J] .Systems Engineering and Theory, 2007, 8:1 -11.

[47] Liu Qin, He Binbin, Lv Zhengchao, et al. Coordination strategy under the overflow of dual- 
channel supply chain service [J]. Journal of Hefei University of Technology: Natural Science Edition, 2014,37(7): 877-882.

[48] But Bin, Xu Guangye, Zhang Xu Mei. Study on the Compensation Strategy of Dual-channel Supply Chain Coordination in E-commerce [J]. Management Engineering, 2012, 26(1) : 125130. 